\title{
Training reference staff prior to consolidating science collections
}

\author{
By Alice L. Primack \\ Bibliographic Instruction Coordinator \\ University of Florida Science Library
}

and Anita L. Battiste

Reference Librarian

University of Florida Science Library

\section{Tours, tests and teamwork as part of the cross-training program before Marston's move.}

\begin{abstract}
$\mathbf{M}$ arston Science Library at the University of Florida is a recently built structure in which were consolidated the agricultural, biological, physical and earth sciences, and mathematics collections from four branch libraries and the main collection (see "The University of Florida's Moving Experience," pp. 467-71). Staff training of reference staff who would be moving to the new building was an integral part of planning and preparation for the move. Two years before the move, a Committee on Cross-Training was appointed. After exploration and discussion, the committee recommended a plan which was approved by the science librarians. The cross-training was extended to include library technical assistant staff who would be working in reference.
\end{abstract}

The goal and objectives of the cross-training were stated as follows:

\section{Goal}

A librarian, after completing the orientation course, should be able to understand and answer most of the reference questions presented at the reference desks in the science library, and should be able to refer all other questions correctly to the appropriate person.

\section{Objectives}

1. The librarian should be able to make effective use of the major abstracting and indexing sources (both print and online) in each subject field to be included in the science library.

2. The librarian should be able to use other major reference tools in general science and in the specific subject fields covered in the science library.

3. The librarian should know the other science librarians and their areas of specialization and feel comfortable asking for their help.

4. The librarian should be familiar with special features and problems of documents, microforms, and maps which will be in the science library.

5. The librarian should be familiar with the major research programs at the University of Florida.

The plan for meeting these objectives included use of tests, tours of existing science branch libraries on campus, lectures, and informal working together.

\section{Implementation}

As the first step in implementation of the plan, questions for use on a pre-test were solicited from librarians in each subject area, and a test was made up of questions selected from these. Some of the questions on the test dealt with all subject areas, such as:

- Name two or three major currently published indexing or abstracting services in the following subject areas: agriculture, chemistry.... 
- Name two to three major journals in the following subject areas (at least one not a society publication): agriculture, chemistry....

Other questions were quite specific, such as:

-Where would you look to answer this question: I want to find out all I can about extracting titanium from beach sands in Florida, especially Jacksonville and Daytona Beach.

And finally the test sought to point up existing subject strengths:

-Which librarians now on the UF staff have a specialty in each of the following subjects: agriculture, chemistry....

The pre-test was distributed to all science librarians and to technical assistants who would be involved in reference. The test was for personal use only in seeing in what areas individuals would like to learn more about reference tools. It was not collected or "graded."

Tours of the existing science branch libraries (Agriculture, Engineering, Physics/Astronomy, and Chemistry) were given at two different times to enable all staff to attend.

The next component of the cross-training consisted of presentations on specific reference materials. These presentations were supplemented by handouts of bibliographies and notes, and published literature guides where appropriate. Again, each presentation was made at two different times in order to allow participation of all reference staff. Presentations were made on the following subject and special format areas: chemistry, earth sciences, engineering, life sciences, mathematics, physics and astronomy, documents, and maps.

Each librarian and reference technical assistant was encouraged throughout the cross-training period to "trail" reference librarians in other areas. For a period of several months schedules were set up between certain branches for "sitting in" on reference duty, and at other times informal exchanges were made.

Individual use of the test was again encouraged after this much of the cross-training program, as a measure of what each person had learned and to point up areas for further study. The same questions as those used on the pre-test were again distributed, this time as a post-test. As before, the tests were not collected or "graded," but were for personal evaluations.

Copies of all bibliographies and other handouts from our cross-training sessions were assembled and placed in notebooks at the two information desks in the new library. Although locations of materials were of course changed, as were some call numbers, these subject listings were consulted by staff dealing with questions in unfamiliar subject areas. Gradually during the course of our first year we developed a series of guides to various subject areas, which were for both patron and staff use. These were generally one page in length and listed titles, call numbers, and locations of major reference tools such as dictionaries, handbooks, indexes and abstracts, and current awareness tools. These subject guides were gathered into a separate notebook at each reference desk, along with other resources such as translations of abbreviations for commonly asked-for periodicals.

In addition, during our first year we instituted a weekly meeting of all reference staff, both professionals and technical assistants. As part of many of these meetings, various staff members made informal presentations on reference tools or on finding specific kinds of information.

\section{Evaluation}

Shortly before the move took place which consolidated branch collections into the centralized Science Library, an evaluative survey of the crosstraining program was done. A survey form was sent to each participant, along with a brief review of what had been done so far in the cross-training. The survey asked how many of the cross-training activities the person had attended, how they rated the overall experience, what were problems and the most and least helpful parts of the training, and what they would like more work in. Results of this anonymous survey showed that most respondents had attended all or most of the activities. Overall ratings of the training process clustered around "moderately helpful," which was the middle rating, with one below and three above. A strong part of the training was getting a generally more comfortable feeling, and getting to know other librarians' areas of expertise. A big problem with the training was lack of time and difficulty in attendance because this meant leaving regular areas understaffed. The consensus was that more training was needed after the move, and that the nature of the training would be determined in part by what would come up-for example, problems with specific reference tools. Overall review and general discussion were also mentioned as important.

\section{Plans for the future}

Plans for the future include continuation of presentations at weekly reference staff meetings. A recent survey at one of these meetings showed definite interest in a wide range of topics for these presentations, ranging from the use of specific reference tools to overviews of categories of the literature.

Planning also takes a direction toward more awareness of major research programs at the university now and in future years. This effort is being helped by the current development of profiles of the various academic programs which are served by the science library, and which are being done primarily as a collection development function. These profiles will be filed in notebooks at the information desks. In addition, we would like to have faculty or librarian-selectors speak about their academic subject areas. 